\title{
Ensaio "Sobre SuJeito E ObJeto" de Theodor Adorno como TRÂNSITO À SUA TEORIA CRÍTICA
}

\author{
[ESSAY ABOUT SUBJECT AND OBJECT BY THEODOR ADORNO AS A TRANSIT TO HIS CRITICAL \\ THEORY]
}

\author{
Cleidson de Jesus Rocha* \\ Universidade Federal do Acre, Brasil
}

RESUMo: É propósito deste trabalho apresentar considerações sobre as teses presentes no conjunto de 12 partes que compõe o texto Sobre Sujeito e Objeto, de Theodor Adorno, relacionando a posição do autor com sua linha biográfica, marcada pelos acontecimentos históricos, bem como pelo itinerário do pensamento filosófico, elementos estes que pautaram a construção de sua teoria crítica. Para tanto, iniciamos com algumas considerações sobre a forma e o conteúdo do texto Sobre Sujeito e Objeto. No segundo momento apresentaremos uma chave de leitura, enquanto possibilidade de organização do texto por seu autor, passando então, a nos deter em cada uma das 12 partes, buscando, além das teses de cada uma das partes, apresentar a interlocução de Adorno com as epistemologias que lhe servem de apoio ao debate em questão. Finalizamos apontando o pessimismo adorniano ao constatar que a força, que tanto se esperou da consciência, não foi suficiente para fazê-la autônoma, pois, ao contrário das promessas iluministas, a racionalidade perde o controle e se desprende de si mesma, convertendo-se verdadeiramente em degeneração da consciência crítica, esvaziando, assim, a condição autônoma do sujeito.

Palavras-ChaVe: Sujeito; Objeto; Theodor Adorno; Teoria crítica
ABSTRACT: The purpose of this paper is to present considerations about the theses present in the set of 12 epigraphs that make up the text About Subject and Object, by Theodor Adorno, relating the author's position with his biographical work, marked by historical events, as well as the itinerary of philosophical thought, elements that guided the construction of his critical theory. To this end, we begin with some considerations about the form and content of the text About Subject and Object. In the second moment, we will present a reading key, as a possibility of organizing the text by its author, and then going to attention on each of the 12 parts, seeking to present Adorno's interlocution with the epistemologies which support the debate in question. We conclude by pointing out Adornian pessimism by realizing that the strength, which was so expected from conscience, was not enough to make it autonomous, because, unlike the Enlightenment promises, rationality loses control and becomes detached from itself, becoming truly in degeneration of critical consciousness, thus emptying the subject's autonomous condition.

KEYWORDS: Subject; object; Theodor Adorno; Critical theory

\section{ApresentaÇão}

noção de sujeito, na qual a modernidade se apegou como instância de A autonomia e liberdade é, segundo Adorno equívoca, porque evoca duas substâncias distintas: o indivíduo particular, como egoicidade, como um certo este aí qualquer e determinações gerais, como uma certa consciência geral, como uma forma

* Pesquisador Colaborador no Programa de Pós-Doutorado em Filosofia na Universidade de São Paulo - USP (2018-2019). Doutor em Filosofia pela Universidade Gama Filho - UGF-RIO (2005). Professor Adjunto no Centro de Educação e Letras - CEL - Universidade Federal do Acre. E-mail: cleidson.ufac@gmail.com 
conceitual universal. A dificuldade do enquadramento do sujeito enquanto categoria filosófica advém do fato de que um conceito pressupõe um movimento de definição, que, em termos congnoscitíveis, significa capturar. A captura, por sua vez, só se sucede mediante as estratégias de um outro, que organiza a busca. Desde logo vê-se que tratar as categorias sujeito e objeto leva em conta um mapeamento de como a filosofia 148 moderna, especialmente a forma idealista assumida por Hegel, tratou essa temática. É o que Adorno pretende tratar no texto Sobre Sujeito e Objeto que passamos a analisar neste trabalho.

A longa discussão de Adorno sobre os dois polos do conhecimento: sujeito $x$ objeto, é permeada pelas polêmicas produzidas pela tradição dialética que enxerga movimentos lineares nos avanços do espírito e/ou do desenvolvimento social. O texto Sobre Sujeito e Objeto é o primeiro de dois "Epilegômenos dialéticos" que Theodor W. Adorno escreveu (o segundo tem o título de "Notas marginais sobre teoria e práxis"). Estes textos, sem data, foram adicionados ao final do livro Stichworte, publicado na Alemanha em 1969, o ano da morte do filósofo e sociólogo de Frankfurt, no número 347 da série da Editora Suhrkamp, que publicou também a obra completa em alemão. A nota dos editores, encabeçados por Rolf Tiedemann explica que Adorno recopilou os textos e fez correções em cópias impressas, para dar maior clareza ao livro que foi publicado logo após a sua morte ${ }^{1}$. Por isso, nos encontramos frente a uma espécie de escritos testamentários.

O texto Sobre Sujeito e Objeto foi traduzido ao português por Maria Helena Ruschel, como parte da dissertação de Mestrado em Filosofia pela Universidade Federal do Rio Grande do Sul, publicada com o título Palavras e Sinais: Modelos Críticos 2, editada pela Editora Vozes em 1995, e contou com a orientação do prof. Álvaro Luiz Montenegro Valls, tendo recebido deste, nas palavras da tradutora, "valiosas contribuições" (ADORNO, 1995, p. 9). No que se refere ao texto original, o prefácio refere que "os epilegômenos dialéticos" são diretamente relacionados à Negative Dialektik, e "estavam destinados a um curso de verão em 1969, que foi perturbado e teve que ser interrompido" (ADORNO, 1995, p. 12).

Depois de todas essas considerações preliminares, podemos começar a trabalhar, buscando identificar a constatação adorniana de que, na presente fase do movimento histórico, assiste-se à plena dissolução do sujeito - que não é mais em si - embora ele ainda creia em sua autonomia. Contra Hegel, que despacha tudo que é individual pelo necessário envolvimento com o pensamento liberal, glorificando a totalidade, Adorno apela a um rompimento das "usanças" dominantes (na ciência, nos negócios e na política), livrando, assim, a arte, a literatura e a filosofia das normatizações estabelecidos pela teoria tradicional, encaminhando, assim, as bases de uma teoria crítica capaz de pautar-se por um comportamento em condições de conservar independência e recusar-se às regras, inclusive do mundo acadêmico.

\section{Considerações sobre forma e conteúdo do texto Sobre Sujeito e Objeto}

Antes de entrar na temática, realizaremos algumas considerações preliminares em relação a dificuldade da linguagem adorniana e a respeito da construção das suas obras, sobre as quais Jay chega a comentar: "Ler um escrito de Adorno ou Benjamin lembra um comentário que, dizem, formulou o cineasta Jean-Luc Godard quando perguntaram se seus filmes tinham um princípio, meio e fim. 'Sim - respondeu -, mas não necessariamente nessa ordem'. (JAY, 1989, p. 289).

Escrever sobre Adorno envolve, antes de tudo, lidar com uma série de possíveis preconceitos nos leitores, preconceitos estes que um de seus tradutores, Andrés Pascual, formulou de uma maneira brilhantemente irônica: "Você tem Adorno por um filósofo mas hermético; por um sociólogo - mas especulativo; por um moralista - mas de coisas mínimas; por uma dialética - mas negativa; por um esteta - mas teórico; alguém parece 
ter ouvido falar que também era analista e crítico de música”. (PASCUAL, 1985, p. 15)

Mesmo que o texto de Sobre Sujeito e Objeto seja breve (21 páginas), é de difícil leitura, situação, pode-se dizer, unânime, quando se trata dos textos do autor frankfurtiano. Na apresentação de tradução da obra Palavras e Sinais: Modelos Críticos 2, onde se apresenta o texto em questão, Maria Helena Ruschel relata que o próprio Adorno refere-se "a quase proibitiva dificuldade de traduzir para outra língua textos alemães” (1995, p. 9). Por isso, ela apela para a utilização de notas de rodapé (onde estão inclusas notas do autor e notas da tradução) e glossário (com notas mais extensas que explanam conceitos desenvolvidos por Adorno, ou próprios da tradição fílosófica). Esse cuidadoso trabalho na apresentação do texto de Adorno, não elimina o esforço de destrinchar - no exercício hermenêutico que ampara as buscas interpretativas como método de investigação-, como ele organizou seu pensamento no texto Sobre Sujeito e Objeto. O texto é composto por frases sintéticas, em 12 partes, onde a linguagem remete a conceitos de outros autores, como Kant e Hegel, sem o domínio dos quais, o texto se faz hermético para o leitor.

Mas, além da linguagem escolhida por Adorno, existem mais dois fatores que acrescentam dificuldade ao texto. Em primeiro lugar, a própria concepção que Adorno tinha do gênero Ensaio, que, segundo escreveu m 1932, devia ser marcado pela ousadia da tentativa, um atrevimento que sempre força o pensamento a persistir na busca. No texto O Ensaio como Forma, diz Adorno:

Na Alemanha, o ensaio provoca resistência porque evoca aquela liberdade de espírito que, após o fracasso de um Iluminismo cada vez mais morno desde a era leibniziana, até hoje não conseguiu se desenvolver adequadamente, nem mesmo sob as condições de uma liberdade formal, estando sempre disposta a proclamar como sua verdadeira demanda a subordinação a uma instância qualquer. $\mathrm{O}$ ensaio, porém, não admite que seu âmbitos de competência lhe seja prescrito. Em vez de alcançar algo cientificamente ou criar artisticamente alguma coisa, seus esforços ainda espelham a disponibilidade de quem, como uma criança, não tem vergonha de se entusiasmar com o que os outros já fizeram. O ensaio reflete o que é amado e odiado, em vez de conceber o espírito como uma criação a partir do nada, segundo o modelo de uma irrestrita moral do trabalho" (ADORNO, 2003, p. $16 / 17)$.

Em segundo lugar, a maneira como o autor de Frankfurt compunha, acatando a sua afeição musical em seus textos, num trabalho artesanal, tecido com idas e vindas ao texto redigido, para corrigir palavras, intercalar novas frases entre as linhas ou referir a outras anotações. Sobre esse processo de trabalho, Rolf Tiedemann, que, além de publicar a obra completa de Adorno em alemão, editou em 2007, as aulas de Adorno sobre A Dialética Negativa, ministradas no inverno de 1965/1966, relata que teve aceso a textos manuscritos de Adorno e neles pode perceber que o autor dava forma a expressão de seu pensamento, anotando frases sintéticas, onde faltam palavras ou onde estas estivessem abrevidas e depois introduzia sucessivas correções, acrescentando palavras e escrevendo na parte superior outras mais precisas ou intercalando entre línhas, outras frases que determinassem melhor sentido às anteriores. Segundo o comentador, tudo isso era feito com uma letra pequena e dificilmente inteligível para outro leitor que não fosse ele mesmo. ${ }^{2}$

Todo esse trabalho de reelaboração resultava num estilo de redação muito semelhante ao de Hegel, que também foi copiado por Marx, a saber, formular uma tese geral e depois explicá-la. Por isso fica difícil resumir o texto Sobre Sujeito e Objeto, porque, reduzir uma epígrafe a uma tese não é fácil, nem pelo esforço da reelaboração, nem pelo movimento empreendido pelo próprio Adorno contra a sistematização, vivamente presente nas filosofias idealistas e por ele repelido. Alertamos, assim, que 
este trabalho não pretende fugir dos assuntos, mas sim promovê-los, talvez com lacunas e dúvidas.

Vale lembrar que Adorno era ciente de que a relação entre a forma e o conteúdo de uma obra colocava problemas hermenêuticos com os quais era preciso contar em favor da coerência teórica. No aforismo 51 da Mínima Moralia, ele ensina:

Primeira medida de precauçãodo do escritor: verificar em cada texto, cada fragmento, cada parágrafo, se o tema central sobressai com nitidez. Quem quer expressar alguma coisa está de tal modo tocado por isso, que se deixa levar sem refletir. A pessoa está próxima demais de sua intenção, 'perdida em seus pensamentos', e esquece-se de dizer o que ela quer dizer” (1993, p.73).

\section{Organização do texto Sobre SuJeito e OBJeto}

As partes que compõe o texto Sobre sujeito e Objeto têm um único parágrafo. Se trata do mesmo estilo fragmentado que encontramos em outras obras de Adorno, como, por exemplo, Mínima Moralia ou Dialética Negativa. Excepcionalmente, o número três tem dois parágrafos, não menos extensos. Pois bem, se dividíssemos o número três em duas partes, e as renumerássemos, nos daríamos conta que Adorno organiza o texto, por assim dizer, por pares: números 1 e 2, número 3 (com dois parágrafos), números 4 e 5 , números 6 e 7 , números 8 e 9, números 10 e 11 e, finalmente, isolado, o número 12. Nesses pares, um parágrafo, geralmente, argumenta desde o sujeito até o objeto e o outro desde o objeto até o sujeito.

\section{DisCUTINDO SENTIDOS DAS/NAS PARTES DO TEXTO}

Nas partes iniciais (números 1 e 2), Adorno explica que a distinção sujeito/objeto é equívoca, porque ambas as noções se baseiam em um par de significados que se envolvem mutuamente. A separação entre sujeito e objeto é uma separação real e ilusória a um tempo, pois não é possível excluir a individualidade humana de qualquer conceito de sujeito, e, por outro lado, o indivíduo singular também é sempre referido a um universal, ou seja, o homem, para particularizar-se como tal, necessita do conceito genérico. Comparece aqui a dialética que vai perpassar todo o texto, que é uma tensão entre o universal e o particular, como no caso aqui, entre o homem singular e o homem genérico. O conceito de sujeito e objeto tem propriedade sobre qualquer definição. Note-se que definições são atribuições humanas, portanto, deflagradas por sujeitos, por meio de estratégias que, pretensamente, traduzem aquilo que os objetos sejam. Os termos sujeito e objeto, lembra Adorno, são adotados tal qual fornece a filosofia, ou seja, um sujeito cognoscente, que se defronta com um objeto do conhecimento.

A parte 2 inicia afirmando que "a separação entre sujeito e objeto é real e aparente" (ADORNO, 1995, p. 182). Real, por que expressa o sentido da condição humana ${ }^{3}$, e aparente por que a separação "não pode ser hipostasiada nem transformada em invariante" (ADORNO, 1995, p. 182). É real por que ela diz respeito a nossa condição atual, ao nosso momento histórico, mas ao mesmo tempo ela é aparente, pois existe um certo grau de falsidade, fazendo com que ela não possa ser tratada como uma natureza, como um em si, uma essência e nem transformada em invariante, ou seja, ela tem um caráter contingencial e varia ao longo da história. Sujeito e objeto se encontram mediados reciprocamente, não sendo possível compreender o conceito de sujeito nem de objeto, excluindo a mediação que um realiza em relação ao outro. A 
interdependência entre ambos vai ser reafirmada ao longo de todo o texto, sob a consideração de que a separação entre um e outro se torna ideologia, se realizada sem considerar a mediação, uma vez que "separado do objeto, o sujeito reduz este a si, o devora, ao esquecer o quanto ele mesmo é objeto" (ADORNO, 1995, p. 183).

Para Adorno, a pretensa identificação de sujeito e objeto é efetivada pela força romântica da construção de verdades convenientes à sociedade. Essa tendência aponta uma nostalgia identificante que vem desde o remoto tempo dos mitos, que esconde e revoga a diversidade, pelo desejo da identificação. O novo horror, o da separação, transfigura o antigo, o caos, que precisou da força dos mitos para ordenar a visão do universo e das coisas. Essa construção só é realizável através do sujeito, que, portanto, não pode ser eliminado, embora tenha que ser "separado" numa forma mais elevada. A eliminação do sujeito operaria a regressão da consciência e a recaída em uma real barbárie. Vislumbrando a ideia kantiana de autonomia, Adorno discute que a submissão à natureza dos mitos procede de uma total menoridade social, de uma época em que a autoconsciência ainda não tinha aberto os olhos, em que ainda não existia o sujeito (ADORNO, 1995, p. 184). Concluindo essa segunda parte Adorno argumenta que uma reconciliação entre os dois polos, só é possível em um estado de diferenciação sem dominação, no qual o diferente é compartido. A isso ele chama de paz.

Os dois parágrafos da parte 3 nos dizem sobre o círculo sujeito empírico/sujeito transcendental. A categorização deste último é resultado da ideia da possibilidade de extração do sujeito do mundo dos indivíduos concretos e dos sujeitos reais, ganhando morada no sublime mundo dos pensamentos puros. Para a teoria do conhecimento o sujeito transcendental é a abstração do homem vivo individual. Porém o conceito abstrato de sujeito transcendental, pressupõe os indivíduos viventes, considerando-se um certo a priori ao indivíduo, ao ser humano singular, o que nos levaria a pensar na possibilidade de um sujeito transcendental a priori. Essa tem sido a forma de argumentar do idealismo, principalmente, da filosofia de Kant, que é apologética, na tentativa de justificar o condicionado como se fosse incondicionado, o derivado como sendo primário, visão que, segundo Adorno, tenta asfixiar a dialética, enquanto constrói uma acepção de sujeito como imutável, fixo e verdadeiro na medida em que não passou pelo devir.

Para Adorno, contudo, o sujeito transcendental é mais real para a conduta dos homens e para a sociedade do que o indivíduo psicológico, que se torna um apêndice da maquinaria social e ideológica. Contudo, ao mesmo tempo, ele afirma que o sujeito transcendental seria uma abstração, uma ideologia, muito embora detenha um caráter de realidade. Bem assim, identifica o efeito que essa abstração tem para a conduta dos homens, para a sociedade, exercendo papel mais determinante do que o indivíduo psicológico: a força do social, no contexto capitalista, tornou os indivíduos um mero apêndice da maquinaria social e da ideologia, sendo, antes uma abstração do que sua própria concretude. Assim é expressa a primazia das relações abstratamente racionais, que tem o seu modelo na troca. O sujeito transcendental é constitutivo da origem de todas as coisas objetificadas. Sua rígida intemporalidade, fixa e invariável tem "a forma reflexa da coisificação dos homens" (ADORNO, 1995, p. 186), ou seja, é presumível uma relação entre a coisificação, a sociedade da mercadoria e esse conceito abstrato de sujeito transcendental, uma vez que a realidade desse sujeito transcendental é um reflexo da coisificação, da reificação da sociedade capitalista, e assim, expressa a verdade sobre a situação histórica alcançada.

No final do primeiro parágrafo da parte 3, Adorno sintetiza o lugar social do indivíduo, nas sociedades capitalistas, nos seguintes termos: "Quanto mais os indivíduos particulares são reduzidos às funções da totalidade social pela sua vinculação com o sistema, tanto mais o espírito, consoladoramente, eleva o homem, como princípio, a um ser dotado do atributo da criatividade e da dominação absoluta 
(ADORNO, 1995, p. 185).

$\mathrm{Na}$ parte 4, Adorno muda seu alvo, que até então estava sendo o sujeito abstrato, transcendental, da filosofia alemã do final do século XVIII e início do XIX, considerando que a primazia do objeto não pode significar uma noção pré-crítica, ou seja, pré-kantiana, que tinha, por exemplo, a sua defesa em filósofos como Hume (ele cita Hume em uma determinada parte) de uma exterioridade em si, independente, completamente, do sujeito. Diz Adorno: "A primazia do objeto significa que o sujeito é, por sua vez, objeto em um sentido qualitativamente distinto e mais radical que o objeto, porque ele, não podendo afinal ser conhecido senão pela consciência, é também sujeito" (ADORNO, 1995, p. 187/188).

A condição de que o sujeito só pode ser conhecido pela consciência, faz dele o que é, por meio da mediação: o sujeito só pode ser, enquanto mediado pela consciência. Desse modo, ao mesmo tempo em que ele é sujeito, ele já é objeto do conhecimento de uma consciência pensante, a mesma que ao apropriar-se de si como objeto, percebe-se consciente de si, ou seja, dotada da autorreflexão, que é a única forma de tornar-se um sujeito.

Adorno é enfático em dizer que considerar a primazia do objeto é um corretivo para esse tipo de redução que vigorou bastante no pensamento filosófico, e afiança: "Somente a tomada de consciência do social, proporciona o conhecimento à objetividade que ele perde ao obedecer as forças sociais que o governam" (ADORNO, 1995, p. 189). Temos aqui uma das teses do texto, norte referente à teoria crítica: o único meio possível de se proceder o interior dessa dicotomia é compreendendo que é a tomada de consciência do social enquanto totalidade histórica, que proporciona um conhecimento da objetividade que a gente perde, ao vivermos no interior dessas sociedades (da alienação, da coisificação, do trabalho, da troca, da mercadoria, enfim). Adorno finaliza a quarta parte se mostrando contra a fenomenologia, que, segundo entende, se equivoca ao dar uma ênfase muito grande à consciência como forma de compreensão, de acesso ao mundo, sem levar em consideração esse caráter do social, que é histórico, e assim determina, tanto o objeto, quanto da própria consciência.

A parte 5 é dedicada a questão da primazia do objeto, que só é legítima em relação ao sujeito se for algo a mais que a coisa em si kantiana, ou seja, se for levada em conta enquanto permeia a intermediação com o sujeito, configurando os conceitos e demais constituições deste mesmo polo. Diz Adorno: "A primazia do objeto comprovase pelo fato que este altera qualitativamente as opiniões da consciência coisificada" (ADORNO, 1995, p. 190). Vemos, assim, que o objeto está o tempo todo alterando as formas de consciência, as opiniões da consciência coisificada, uma vez que as sociedades da troca, da mercadoria, estão, o tempo todo, ditando, determinando, a consciência dos homens. Finalizando este item, Adorno restabelece a dialética entre sujeito e objeto, nos seguintes termos: "Mas como a primazia necessita da reflexão sobre o sujeito e da reflexão subjetiva, a subjetividade, ao contrário do que ocorre no materialismo primitivo - que não admite propriamente dialética - converte-se aqui em um momento conservado" (ADORNO, 1995, p. 190). Adorno critica a ratio das modernas ciências da natureza, que, segundo ele, olham por cima do muro erguido por elas próprias, construindo categorias a partir de um distanciamento dos fenômenos, em nome de uma neutralidade axiológica, abalando o subjetivismo e desconsiderando que o homem é feito pelos homens, desencantando, assim, a propriedade criadora do espírito.

As partes 4 e 5, acima tratadas, merecem explicações maiores. Aqui, definitivamente, Adorno formula uma tese que procede da sua leitura de Kant, e por leitura entendemos aqui não uma mera interpretação, mas todo um arco biográfico que vincula dois momentos separados no tempo e que, naturalmente, não se explica no texto. Vejamos os fatos que seguem:

Em 1918, Adorno conheceu Siegfried Kracauer, com quem passou a ler 
regularmente aos sábados à tarde a Crítica da razão pura de Kant: "Sob sua direção, desde o princípio, experimentei a obra não como uma mera teoria do conhecimento [...], mas como uma espécie de escritura codificada a partir da qual se podia ler o estado histórico do espírito [...]." ${ }^{4}$ Mais de quarenta anos depois, no semestre de verão de 1959, Adorno deu, na Universidade de Frankurt, um curso sobre a Crítica da razão pura de Kant. Nesse curso, Adorno defende uma interpretação da primeira Crítica em que o objeto sempre tem um resto indócil à apreensão do sujeito; uma leitura que classificaria mais materialista que empirista, uma vez que a leitura de Adorno é antifenomenológica e não é inconciliável uma interpretação empirista e fenomenológica.

Esse curso de 1959 inicia um período de sete anos em que Adorno, por assim dizer, se concentra em lançar Hegel (a dialética) contra Kant (e os neokantianos), mas também Kant (a primazia do objeto) contra Hegel (e sua positividade) e fricciona um com o outro para trazer à tona a Dialética negativa (1966), onde, desde as primeiras páginas da obra (se vê na primeira epígrafe: ainda é possível a filosofia?) se mantém este jogo no texto como sua engrenagem principal, em que articulam outros (como os comentários sobre Marx ou as críticas a Heidegger). ${ }^{5}$

Portanto, é promissor apostar na configuração de um arco biográfico que vai de Kracauer à Dialética negativa, de ler a Crítica da razão pura como "estado histórico do espírito", a entendê-la como chave para abandonar a dialética positiva ou para trazer à tona uma negativa e também para deixar de lado o idealismo.

Quanto a parte 6 podemos dizer que ela gira em torno de uma frase central do parágrafo: "O a priori e a sociedade estão entrelaçados, estando uma na outra e viceversa. Isto é, a sociedade está no a priori e o a priori está na sociedade. (ADORNO, 1995, p. 191), Antes da frase citada, na primeira metade da epígrafe, Adorno argumenta a primeira parte da afirmação, a saber, que a sociedade está no a priori; depois dessa frase, explica a segunda parte desta tese.

Inicia referindo-se que a ilusão do fenomenalismo repousa no fato de que "nada se sabe senão através do sujeito cognoscente" (ADORNO, 1995, p. 190). Essa ilusão, é, segundo ele, necessária e tem a sua importância, pois testemunha o contexto geral de ofuscamento que o sujeito, enquanto falsa consciência, produz, e da qual é, ao mesmo tempo, parte integrante, dando testemunho desse momento de ofuscamento, que os indivíduos se encontram. O fenomenologismo constrói uma falsa consciência, fundando a ideologia do sujeito, que infunde um narcisismo coletivo. Nas palavras de Adorno: "Aquilo que a filosofia transcendental exaltou na subjetividade criadora é o cativeiro do sujeito em si, oculto para ele mesmo" (ADORNO, 1995, p. 191).

Perante o cativeiro o sujeito cognoscente submete-se à dependência em relação ao "espaço, o tempo e as formas de pensamento" (ADORNO, 1995, p. 191), que "marcam justamente sua dependência em relação à espécie" (ADORNO, 1995, p. 191). Verifica-se que, mais uma vez, o materialismo aparece como a primazia da espécie em relação ao sujeito cognoscente. Assim Adorno entende que o a priori e a sociedade estão entrelaçados, que o indivíduo não é menos cativo dentro de si que dentro da sociedade, uma vez que "o cativeiro categorial da consciência individual reproduz o cativeiro real de cada indivíduo" (ADORNO, 1995, p. 192). O cativeiro real é justamente a sociedade do trabalho, alienante, etc.

A primeira metade do parágrafo conclui que a espécie "se precipitou" nos constituintes do conhecimento (as formas a priori). Dito assim, essa afirmação poderia ser assinada por Hegel, por exemplo. Primeiramente, seria suficiente substituir "espécie" por "espírito" e "constituintes do conhecimento" por "saber absoluto". Definitivamente, o real se torna racional, diria Hegel. Ambos coincidiriam também no que afirma o texto, a saber, que assinalar a gênese (social) dos constituintes não lhes agrega valor. Mas como veremos, Adorno não para por aqui. 
Após esta exposição, relativa à primeira parte da frase que norteia a discussão de Adorno nesta parte 6 ("O a priori e a sociedade estão entrelaçados estando uma na outra e vice-versa") (ADORNO, 1995, p. 191) o argumento de Adorno se centra na segunda parte da tese, a saber, que o a priori está na sociedade, porque a universalidade e necessidade das formas de o apriori são o que constitui aos seres humanos como unidade. Mas antes de nos concentrar na discussão sobre a segunda parte da tese, voltaremos à primeira parte.

O texto da epígrafe começa com uma crítica ao fenomenalismo. Contudo, vale alertar que o leitor não deve cair no erro de identificar o fenomenalismo de que Adorno fala aqui com algumas versões do empirismo ou do positivismo, derivadas, por exemplo, do Círculo de Viena ou da Escola de Berlim. Acreditamos que a noção tem um perímetro muito maior, porque Adorno não está se opondo a uma escola filosófica, mas descrevendo uma série de pontos de engano, que é necessário distinguir, uma espécie de escada com degraus que se ocultam sucessivamente:

a) Existe uma "ilusão", ou melhor, uma aparência, que consiste no encantamento do sujeito em seu fundamento próprio de determinação, isso é, no erro da sua consideração da sua posição como verdadeiro ser.

b) Sobre aquela aparência, tem uma segunda capa de ocultação: o sujeito produz uma "trama de ocultação", o que resulta irresistível.

c) Nesta irresistibilidade, se funda a "ideologia do sujeito", patrocinada pelo "narcisismo coletivo".

d) Um passo adiante, essa ideologia se define em filosofias que Adorno classifica como "as [...] mais formidáveis".

O que Adorno está fazendo? Pelo que vemos, ele produz um atrito de Kant contra Hegel, enquadra a fenomenologia do espírito em um contexto de aparência, encobrimento, ideologia, portanto, definitivamente, erro; um erro necessário, mas um erro. Por isso, a afirmação final: que a gêneses (social) dos constituintes nem por isso são menos vigentes.

Logicamente, o enquadramento que Adorno faz, entre outras coisas, é uma crítica avant la lettre do pós-modernismo, porque marca com extraordinária precisão a sua manobra teórica principal: desmontar a noção de ideologia, diluir o erro em relativismo.

Pode-se deduzir que, se na primeira parte da número seis, Adorno lança Kant contra Hegel, na segunda acontecerá o contrário. É nisso que opera a tese: "o cativeiro categorial da consciência individual reproduz o cativeiro real de cada indivíduo" (ADORNO, 1995, p. 192). Adorno aceita do autor da Fenomenologia do espírito precisamente a possibilidade de projetar ("como um contorno de sombras", diria Hegel) o ponto da consciência na constituição real do ser humano. O racional resulta no real.

A seguir, a número 7 parece seguir o caminho percorrido pela número 6 . Da mesma forma, começa levantando contra uma filosofia determinada (neste caso, um reducionismo como o de Russell que, na sua primeira época, se autodeclarava neorrealista). Mas, cumpre advertir que os ataques de Adorno não só vasculham um espaço teórico muito mais amplo, mas também apontam uma característica da época: a época da impotência subjetiva. No caso de Russell e outros positivistas, fica claro que apresentam uma "filosofia" (se colocam as aspas porque os positivistas radicais alguns do Círculo de Viena ou da Escola de Berlim - não a classificariam assim) "antisubjetivista", mas em aparência, assinala Adorno. É subjetivista na realidade, e este subjetivismo foi criticado na parte anterior.

Verificamos ainda na parte 7, que Adorno muda a mira crítica em direção ao pensamento da identidade antisubjetivista, neorrealista, que, segundo entende, é a forma contemporânea da consciência coisificada, reducionista, por causa de seu subjetivismo latente, que mal entende a si mesma. Dessa maneira, o pensamento da identidade 
revoga a si mesmo, fazendo fracassar a hipótese de uma ciência prática enquanto reflexão residual após a retirada do sujeito. Denota-se que para Adorno não é possível acesso ao objeto sem essa mediação reflexiva do sujeito, como quer a ciência, ou o neorrealismo antisubjetivista. Assim diz Adorno: “A representação que guia o conceito residual de objetividade também tem seu protótipo em algo posto pelo homem. Esse modelo é o lucro, daquilo que resta no balanço uma vez deduzidos os custos gerais de manutenção" (ADORNO, 1995, p. 193). Objeto e sujeito estão longe de validarem sua existência um sem o outro. As determinações de um e de outro, embora hostis, adaptam-se à chave dialética que sustenta a existência de ambos.

No referente aos métodos científicos, que buscam anular um ou outro, separando-os, como essências puras, assim diz Adorno: "o resto, com o qual a ciência se satisfaz, é produto do seu proceder manipulativo, subjetivamente organizado" (ADORNO, 1995, p. 193). A ciência, na sua auto ilusão de produzir um objeto que ela considera que tem em si o seu nível de pureza, na verdade esquece que este objeto é subjetivamente organizado. Esse "resto" que ele chama aqui, é um reflexo da própria manipulação do cientista, embora este não o leve em consideração.

A objetividade só pode ser descoberta por meio de uma reflexão, sobre cada nível da histórica e do conhecimento; a objetividade não pode ser tratada como algo que sempre esteve aí, independente das estratratificações, dos paradigmas históricos. O diferencial válido do sujeito do conhecimento é a experiência, que abarca a compreensão dialética da relação sujeito $x$ objeto, extinguindo "a violência contra o objeto. $\mathrm{O}$ ato aproxima-se do conhecimento quando o sujeito rasga o véu que tece ao redor do objeto" (ADORNO, 1995, p. 194). Então o sujeito deve ser considerado em relação ao objeto, como algo que está agindo ali, mesmo que dialeticamente, em relação a esse objeto, e não constituindo esse objeto, não pondo esse objeto a partir dessa atividade subjetiva. O sujeito é um agente em relação ao objeto e sua ação materializase na experiência de lidar com as informações, conceitos e naturezas dos objetos que têm em conta em sua vivência social e em seu mundo psicológico.

Na parte número 8, Adorno argumenta que não "existe" objeto propriamente. Este é um parágrafo onde ele se atém bastante ao pensamento de Kant, ponderando que "o sujeito substitui o objeto no extremo de sua pretensão formante. Isso, entretanto, também tem sua razão paradoxal, pois o sujeito é também objeto, só que, independizando-se como forma que esquece como e por meio de que ele mesmo foi construído" (ADORNO, 1995, p. 195). Adorno conclui a parte 8, colocando as duas ideologias que ele visa combater, que é a percepção originária do sujeito abstrato e também o modelo das ciências da natureza.

Na número 9, afirma que não "existe" sujeito propriamente". Na número 10 argumenta que o sujeito não existe sem objeto e na número 11 que o objeto não existe sem sujeito. As epígrafes 8, 9, 10 e 11 nos parecem consequências da número 7, com um toque de um virtuosismo dialético (no sentido medieval do termo). Prepara-se, assim, uma nova parte, a final, que se volta sobre a relação reflexão/sociedade. Deste modo, o texto da parte 12 se organiza em duas. Abre com o seguinte trecho: "a reflexão do sujeito sobre seu próprio formalismo é uma reflexão sobre a sociedade" (ADORNO, 1995, p. 199). Novamente, aqui a afirmação de Adorno é mais profunda do que parece.

Vale a pena lembrar as contribuições da Escola de Frankfurt e seu entorno sobre o processo de massificação e formação cultural das massas - responsável pela implementação de uma racionalidade instrumental. Também sob seu guarda-chuva, Adorno desenvolveu o projeto de investigação sobre a personalidade autoritária, apontando uma pré-disposição das massas em acatar a servidão frente à projetos autoritários de poder. $\mathrm{O}$ fundamento da tese inicial da parte 12, como já afirmou Adorno ao longo do texto, está no fato de que os "formadores constitutivos" do conhecimento se originam na sociedade, sendo delas a sua expressão e forma. Assim sendo, quais os 
componentes de resistência e emancipação possíveis? Como romper grilhões que estruturam os conhecimentos em semi-formação generalizada? Como levar a teoria a escapar de seu viés tradicional, que em tudo colabora para a imposição da ideologia dominante? Como desenhar possibilidades de uma ciência crítica?

\section{TrÂNSITO À TEORIA CRÍTICA}

Segundo Adorno, a função cognoscente precisa ser restaurada. Aos "formadores" embrenhados na experiência objetivante da sociedade do consumo, no "cativeiro objetivo do sujeito dentro de si" (ADORNO, 1995, p. 199), caberá fazer emergir a teoria crítica como chave para a definição de um novo conceito de conhecimento. Os formadores, ainda que objetificados e por isso mesmo, debilitados, ainda assim são sujeitos e sem eles não há objeto. A condição da individualidade é parte integrante do mundo empírico e é dela que predica-se o conjunto do mundo social. Abster-se da ousadia de tentar, colocaria o sujeito literalmente, perdido em si mesmo, recluso em seu próprio sumiço. Voltemos, assim, sobre um tópico já enunciado no número seis: "Seu cativeiro foi interiorizado: o indivíduo não está menos cativo dentro de si que dentro da universalidade, da sociedade. Daí, o interesse em mascarar sua prisão como liberdade. O cativeiro categorial da consciência individual reproduz o cativeiro real de cada pessoa singular" (ADORNO, 1995, p. 192/193).

As inquietações de Adorno, aqui apresentadas, sinalizam sua visão sobre as formas como a epistemologia tradicional trata a relação sujeito x objeto, apoiada numa fragmentação que dá à cada ciência, uma parte dos objetos de investigação. À sociologia, a psicologia social, a economia, a filosofia - dividiam o mundo dos interesses epistemológico entre si. Esse processo, embora resultasse no que os cientistas chamavam de refinamento das pesquisas, tinha um efeito reverso, ao separar a pesquisa teórica da empírica, bem como no que corncerne à crítica que deve permear os aprofundamentos de qualquer estudo científico. Por essas razões, a teoria crítica pretende ocupar o lugar da interdisciplinaridade, que assume a amplitude na abordagem de quaisquer assunto em estudo, especialmente demarcando os aspectos que se entrecruzam em relação aos fenômenos, tais como os econômico, os sociais, culturais, etc. Ou seja, a teoria crítica reinvidica o lugar do diálogo com os contextos vividos, enxergando a constituição do peso do social sobre a forma de compreensão da realidade, buscando, outrossim, intervir na abolição do sofrimento do mundo. Dessa maneira, repudia os modelos e situações ideais, tanto enquanto método de pesquisa, quanto como parâmetro comportamental, seja político, social, cultural, econômico e assim por diante, e propõe a abolição do sofrimento, por intermédio das transformações sociais.

Sobre a teoria crítica de Adorno preocupa-se, como vimos ao longo deste texto, não apenas com o conteúdo dos fenômenos estudados, mas também com a metodologia utilizada para a construção das respostas. O texto em discussão neste trabalho demonstra uma espécie de metateoria, enquanto ocupa-se não apenas de trazer à tona as discussões do corpus filosófico, que debruça-se sobre objetos diversos, mas também a forma como se produzem essas narrativas e como se elaboram os conceitos. Vimos, por exemplo, a clara demonstração das diferenças na relação sujeito e objeto na teoria tradicional e na teoria crítica, nas marcas que a última imprime para um e para outro, em codeterminações múltiplas. A abissal distância que separa o sujeito do objeto na teoria tradicional é superada nos avanços e aproximações que resultam da confrontação entre um e outro na teoria crítica, que se faz, assim, capaz de esvaziar a pretensão classificatória, de dominação da primeira, imprimindo possibilidades emancipatórias do sujeito na última. 


\section{CONSIDERações FinAis}

Para Adorno, a força que tanto se espera da consciência não foi suficiente para fazê-la autônoma. Assim, constitui-se como mero engano. Este engano é reconhecível facilmente, pois verifica-se que a racionalidade perde o controle e se desprende de si mesma, convertendo-se verdadeiramente em mitologia: a ratio se converte em irracionalidade voltando-se contra si própria, no investimento de fazer desaparecer seu próprio substrato. Quando o pensamento segue inconscientemente a lei de seu dinamismo, acaba se voltando contra seu próprio sentido.

A degeneração da consciência é, para Adorno (2009), produto de sua carência de reflexão crítica sobre si, já que o pensamento tradicional optou por tomar a identidade por seu objetivo, desconsiderando a importância do movimento da consciência sobre si própria. Assim, apostando na certeza de que o objeto é dono da verdade, arrisca-se a encontrar apenas a aparência de identidade, que também se manifesta como pensamento. Os espasmos desse engano entre o que é e o que não é também são atributos do pensamento, que os identifica para os negar, ou então, quando inapto, se engana, considerando o erro como verdade. O pensamento tradicional, ao abrir mão da crítica, adormece sobre os escombros de suas realizações malsucedidas. Obcecado pela identidade, a lógica da modernidade anula o estatuto do sujeito, substituindo sua pretensão de autonomia por um nulo movimento de repetição do já pensado, replicando assim, o movimento espiral que enrosca o pensamento entre sujeito e objeto e deste ao sujeito, e, quando muito, enleva os achados dessa relação, para um plano geral, instituindo conceito como movimento último da/das consciência/as.

Para Adorno, supor a existência de uma certa verdade pura é mera ideologia, já que nessa suposição embute-se a compreensão de que a verdade é a não existência da contradição nem de antagonismo algum. Cristaliza-se a ideia de uma supremacia de um tal conceito, que, concluído por um método seguro, passa a ser indubitável e por isso mesmo, válido para todos, em todos os tempos.

A crítica adorniana à ontologia tradicional diz respeito a atitude escapista em enfrentar o quadro social bastante claro, mas pouco visto pela tradição. É patente que com a entronização dos grupos que detém o poder no lugar do sujeito social, produz-se a ameaça internacional do fascismo, com a eminência de que o progresso se converta em regressão, como a humanidade já pode testemunhar, com o fenômeno do fascismo e nazismo. O caráter drástico dessa situação é que nada garante que a sociedade esteja vigilante para que fatos equivalentes não venham a acontecer. Por outro lado, lembra Adorno, o consumismo exacerbado liquida a metafísica, e os objetos do consumo se tornam, eles próprios, metafisica, a partir da eficiente lógica da construção do desejo, em voga com as operações da indústria cultural. A falência da razão faz imperar a pretensão de pensamento que se considera autossuficiente e que tem por princípio básico sua hegemonia absoluta em relação a práxis social. Não obstante, a sensação de megalomania oferece um irônico conforto, já que não deixamos de fazer a insistente pergunta de como nos comportar para sermos reconhecidos como "sujeitos" e não párias sociais. A pretensão da identidade apenas nos situa, como nos relatos míticos, como seres idênticos, aprisionados em relações previamente determinadas. Essa mesmice é sempre perigosa, pois caminha de mãos dadas com o conformismo e com a resignação ao horror.

A pretensão científica de alcançar a verdade como correspondência entre a noção e a coisa percebida, a adequação entre conceito e objeto, se torna impossível para a dialética, que leva em conta a diferença entre sujeito e objeto. Entra em jogo então o sentido da "mediação", por meio da qual a reflexão filosófica procura situar sua pretensão de verdade, sob o risco de abdicar de seu poder crítico e reflexivo e sua ancoragem no ideal de emancipação. 


\section{REFERÊNCIAS}

ADORNO, T. W. "Sobre Sujeito e Objeto", IN: Palavras e sinais: Modelos Críticos 2. Tradução: Maria Helena Ruschel. Supervisão de Alvaro Valls. Petrópolis-RJ. Vozes, 1995.

ADORNO, T. W. "Ensaio como Forma", In: Notas de Literatura I. Tradução e apresentação de Jorge M. M. de Almeida. São Paulo: Duas Cidades; Ed. 34, 2003.

ADORNO, T. W. Dialectica Negativa. Versión española de José Maria Ripalda. Madrid: Taurus, 1975.

ADORNO, T. W. Dialética Negativa. Tradução Marco Antônio Casanova. Rio de Janeiro: Zahar, 2009.

ADORNO, T. W. Minima morália: reflexões a partir da vida danificada. Tradução de Luiz Educardo Bica. São Paulo: Ática, 1993.

ADORNO, T. W. Vorlesungen über Negative Dialektik, Nachgelassenen Schriften, XVI, Fráncfort d. M.: Suhrkamp, 2007

ARENDT, Hannah. A condição humana. Tradução de Roberto Raposo. $10^{\mathrm{a}}$ ed. Rio de Janeiro: Ed. Forense Universitária, 2007.

CLAUSSEN, Detlev. Theodor W. Adorno, Valencia, Publicacions de la Universitat de València, 2006.

JAY, Martin. As ideias de Adorno. Tradução Adail Ubirajara Sobral. São Paulo: Cultrix Editora da Universidade de São Paulo, 1988.

JAY, Martin. La imaginación dialéctica. Una historia de la Escuela de Frankfurt, Madrid, Taurus, 1989, p. 289.

PASCUAL, André Sánchez. Nota preliminar de Adorno. In: Impromptus. Serie de artículos musicales impresos de nuevo. Barcelona: Ed. Laia, 1985.

TRAVERSO, Enzo. Siegfried Kracauer. Itinerario de un intelectual nómada, València, Alfons el Magnànim, 1998.

\section{Notas}

1 Cf. ADORNO, T. W. Vorlesungen über Negative Dialektik, Nachgelassenen Schriften, XVI, Frankfurt: Suhrkamp, 2007.

2 Cf. ADORNO, T. W. Vorlesungen über Negative Dialektik, Nachgelassenen Schriften, XVI, Frankfurt: Suhrkamp, 2007.

3 Cf. Arendt, Hannah. A condição humana. Rio de Janeiro. Ed. Forense Universitária, 2007. Nesta obra a filósofa alemã discorre sobre o natureza de cada uma das atividades inerentes à condição humana, que são: o labor (que diz respeito ao um processo biológico executado pelo corpo vivo); o trabalho, (que é uma atividade que produz um mundo "artificial" de coisas, que destinam-se a transcender todas as vidas individuais) e a ação, que é a atividade exercida entre "homens", correspondente à pluralidade da condição humana.

4 Enzo Traverso: Siegfried Kracauer. Itinerario de un intelectual nómada, Valência, Alfons el Magnànim, 1998, p. 31.

5 Detlev Claussen: Theodor W. Adorno, Valencia, Publicação da Universidade de Valência, 2006, pp. 67-81 